\title{
THE PERCEPTION OF SOUTH AFRICAN PARENTS ON THE USE OF TECHNOLOGY IN SCHOOLS
}

\author{
Machdel Matthee, Marié Hattingh, and Lizette Weilbach \\ Department of Informatics, University of Pretoria, South Africa \\ \{machdel.matthee, marie.hattingh, \\ lizette.weilbach\} @up.ac.za
}

\begin{abstract}
Parents are recognized as an important group of stakeholders to take into account when implementing technology in schools. However, very little research has considered the parent's view in the learning development of his/her child, when introducing technology. This paper addresses this gap by presenting the findings of an inductive study to improve the understanding of parents' perceptions on the adoption of technology in their child's learning environment. A qualitative study was done with data gathered through an online anonymous questionnaire containing open-ended questions. The questionnaire was distributed on parents' communication platforms. The data indicated that the introduction of technology has caused concern amongst parents. The parents sensed that their children's (inter alia) academic goals, neurological development, competency in computer usage and health, are affected by the introduction of technology. They experienced an increase in difficulty to monitor learning; some children find it more difficult to study and that children are easily distracted. The parents managed these interferences by amongst others acquiring hard copy textbooks; adjusting the way they monitor homework and agreeing to trust their children rather than attempting to monitor everything. The findings illustrate the importance of involving parents in the technology implementation process because of their close involvement in the academic development of their children (especially primary school children).
\end{abstract}

Keywords: Parents, Technology, Learning Environment, School, e-Textbook

\section{Introduction}

Educational technology is increasingly introduced in South African schools - albeit with mixed results. The resistance of especially teachers to accept this technology has been well documented (Weilbach \& Matthee, 2016; Zhao \& Cziko, 2001). The implementation of technology in schools provokes change and the success of such an implementation according to Lim et al. (Lim, Zhao, Tondeur, Chai, \& Tsai, 2013), depends to a large extend on its compatibility with the learning and teaching environment. Several authors emphasise the importance of understanding and managing these changes. $\mathrm{Ng}$ and Nicholas (Ng \& Nicholas, 2013) call for a people-centred framework when implementing mobile technology in schools to accommodate both 
the technical and the people-related aspects involved. These include management, teachers, learners, technicians and the wider community.

The 2010 US National Science Foundation's (NSF) Roadmap for Education Technology (Spector, 2013) advises that employers, parents, administrators, teachers and students should be consulted regularly to build their confidence in systems implemented in schools. Parents are considered important stakeholders, but despite this, there is a lack of research that takes into account the role of parents in the implementation of technology in education.

The authors of this paper have had some informal discussions with the teachers, learners and parents of a local school, where information technology was implemented. Chrome books were rolled out to grade 4 to 12 learners, with a blended learning platform aimed at making the creation, distribution and grading of learner assignments paperless, together with an interactive e-textbook reader - all printed textbooks were replaced with e-textbooks. This implementation created quite a stir amongst parents and we subsequently decided to investigate the concerns.

This paper consequently aims at reporting on the perceptions of South African parents regarding their children's learning environment and their role in it when technology is integrated into it. The research is intended to assist principals and other decision makers with ways to approach parents during the decision making process to implement technology in schools.

\section{The use of educational technology in schools}

Educational technology refers to the use of a wide variety of technologies aimed at the facilitation of educational practices (Kinshuk, Huanh, Sampson, \& Chen, 2013). It has become synonymous with the terms computer based learning and online education. The New Media Consortium's 2010 Horizons report highlights electronic books and mobile devices as two technologies to observe in the "near future (one year or less)' category. These technologies are indicated as well-known technologies that have already made their way into the educational context as is the case in the school we investigated.

An e-textbook is a subset of the e-book category and comprises of educational material in an electronic environment (Landoni, Wilson, \& Gibb, 2000). Learners are able to underline important aspects, write notes and lookup new and unfamiliar words or definitions. Other advantages include the portability on light mobile devices and an extensive search facility (Cavanaugh, 2002; Lam, Lam, Lam, \& McNaught, 2009). However, Embong et al. (Embong et al., 2014) report that learners will only use ebooks if their teachers and their school establish a suitable e-book environment.

To successfully implement technology in schools, such as e-book readers and a Learning Management System (LMS), all stakeholders (school board members; the principal; teachers; technologists; parents; and policy makers) have a specific role to play in the successful adoption of and adaption to the new technology. LMS's combines a range of subject administrative management tools, as well as instructional 
tools which allow educators to design, build and deliver online learning environments (Coates, James, \& Baldwin, 2005).

While the school board members may consider the role the technology could play to help them attain the school's mission, the teachers will focus on adapting to the usage of the new technology when performing their teaching task and the support they would need to implement it successfully. The school principal has to deal with how the implementation will affect the school's administration, schedules and technology infrastructure, while the parents will have to consider the implications of this new close connection their children will now have with the technology on their educational outcome, as well as the intended and unintended costs associated with implementing the new technology (Windschitl \& Sahl, 2002).

\section{$3 \quad$ Research Design}

A qualitative study was done with data gathered through an online anonymous questionnaire containing open-ended questions. Convenience sampling was used by making the questionnaire available on the school's official communication platforms. Parents of grade 4 to 12 learners, who have been on the receiving end of the revolutionary implementation of technology in their child(ren)'s school, were invited to participate in the study. Only thirty-nine parents out of a possible 500 households participated. $80 \%$ of the respondents had children under 12 years old. The questionnaire included seven questions dealing with 1) parents' attitude towards technology in general, 2) their opinion regarding the use of technology in schools, 3) what they consider as risks associated with the use of technology in schools, 4) to what extent the technology meets their expectations, 5) to what extent the technology makes them vulnerable, 6) how dependent they are on technology to help their children meet their educational needs and 7) what the school can do to help them with this transformation process. These responses were analysed (see section 4) and the findings and some recommendations have consequently been communicated to the school principal and management in a written report format.

\section{Data Analysis}

Thematic Analysis (TA) was used to analyse the data. As TA is typically used to analyse written, verbal or visual messages it was ideally suited to analyse the qualitative responses obtained through the online questionnaire used to obtain the data. Clarke and Braun (Clarke \& Braun, 2013) describe TA as a theoretically independent method to identify and analyse patterns in qualitative data. The responses to the questions were coded after which themes were identified from the codes. The focus of the analysis was on the negative responses. The emerging themes can be explained as: the integration of technology in their children's learning environment results in parents with concerns accompanied by negative emotions. This leads to parents taking corrective actions or wanting corrective actions to be taken by the school. Positive par- 
ents (the minority), felt excited about their children being prepared for the technological age.

Table 1 below summarises the concerns expressed by parents.

Table 1. Concerns caused by technology emerging from the data

\begin{tabular}{|c|c|}
\hline Concerns & Examples of remarks \\
\hline Concern about over-emphasis of IT & $\begin{array}{l}\text { "Technology should not be overused. There is no replacement for an in- } \\
\text { volved teacher." }\end{array}$ \\
\hline $\begin{array}{l}\text { Concern about studying using e- } \\
\text { textbooks (going paperless) }\end{array}$ & $\begin{array}{l}\text { "I think they are way too young to go completely paperless and are expected } \\
\text { to study without textbooks. It is extremely difficult to study directly from a } \\
\text { computer screen." "Worldwide trends go back to books". "Children have to } \\
\text { keep referring to different pages in different sections causing some infor- } \\
\text { mation to be missed! NOTHING is printed for parents nor children to review } \\
\text { what's being learnt. My opinion: it has resulted in such a steep learning } \\
\text { curve for our children resulting in poorer marks, no typing skills so time } \\
\text { consuming so overall not something I would recommend" }\end{array}$ \\
\hline $\begin{array}{l}\text { Concern about neurological and other } \\
\text { fundamental development of child }\end{array}$ & $\begin{array}{l}\text { "Physical writing however should still take priority over electronics". } \\
\text { "Children are not playing before school!!!" }\end{array}$ \\
\hline Concern about health of child & $\begin{array}{l}\text { "Too much screen time impact on concentration and the child's ability to } \\
\text { stay focused as it influences their alertness levels". " } \\
\text { Movement is medicine and screentime hampers that." } \\
\text { "I also think it is bad for their eyes." }\end{array}$ \\
\hline $\begin{array}{l}\text { Concern that child is too young for } \\
\text { full implementation }\end{array}$ & "I think it is beneficial for older children" \\
\hline Concern about cyber safety & $\begin{array}{l}\text { "I have found that the googling search functionality is not as secure as I } \\
\text { would like and depending how the kids word a search, some undesirable } \\
\text { search results inevitably get through." } \\
\text { "If not monitored, our kids may be exposed to cyber bullying and access to } \\
\text { inappropriate content" }\end{array}$ \\
\hline Concern about distractions & "Playing games as you can't monitor what they are doing" \\
\hline $\begin{array}{l}\text { Concern that child is given too much } \\
\text { responsibility }\end{array}$ & $\begin{array}{l}\text { It is our belief that there are more gaps in the education framework with the } \\
\text { use of ICT in education taking the control and centralization of the education } \\
\text { away from the parents and educators, placing this management and control } \\
\text { into the hands of the child/student who, in our opinion, is ill-equipped to } \\
\text { handle this level of responsibility and accountability." }\end{array}$ \\
\hline Concern about extra costs & $\begin{array}{l}\text { "I see this as a cost saver and convenience to the school, at the detriment of } \\
\text { the pupil. The printing costs have just been passed to the parents. Lots of } \\
\text { parents are complaining that it takes longer to find the work to be done, than } \\
\text { doing the actual work. Also, some parents are buying the text books any- } \\
\text { way, because the pupils struggle to read the screens." }\end{array}$ \\
\hline
\end{tabular}

The concerns listed above led to negative emotions such as loss of control and helplessness. "I feel out of control as I do not have something physical in my hand because I cannot print etc."; "My authority as parent is undermined", "I am a very concerned and worried parent. Above all, with very little say in what I think is good and not good for my child. That is distressing!"; "All control that the parent did have, based on a full or partial paper based learning framework, has, literally, overnight been removed and placed in the hands of the student (child) who is ill-equipped to take on this responsibility."

Parents expressed their need for the school to take corrective actions by providing training and improved communication with parents: "Parents should have been informed what the benefits are of using Chromebooks, based on extensive research conducted by the school. I am not convinced that such research was actually done. It seems to me that the school simply wanted to follow the latest trend. Trends, unfortunately, cannot be trusted as good indicators of what is beneficial for our kids." They 
also expressed their wish for a more gradual implementation, rules regarding the use of chrome books during breaks and before school, limiting the implementation only to secondary school learners, the availability of a helpline and training in cyber safety.

The parents themselves took corrective actions by obtaining information from other parents via social media, monitoring the application all the time since "teachers seemingly post work at random times", monitoring their child's computer use to protect them from cyberbullying and access to inappropriate content, acquiring the hard copy textbooks, printing out study material, consulting educational psychologists regarding health and neurological developmental concerns and monitoring eye deterioration. Some parents simply decided to trust their children more.

\section{Discussion}

Only a small percentage of the school's parents responded to the questionnaire. A possible interpretation could be that only a small percentage of the parents are concerned. However, we believe that only a small percentage felt determined enough to participate in the survey. Other parents might have felt that technology integration is inevitable and unstoppable and they therefore saw no point in participating in such a survey. Should these concerns then be ignored? We believe that it should be heard and addressed - cyber safety for example is a real danger and parents should be made aware of the dangers and how to protect their children against it.

Although most respondents expressed negative feelings towards the technology integration, a small number of respondents were decidedly positive: "The world is moving and our kids must be exposed and assisted to adapt to the changing world. I am super exited". Some pointed out the improved communication between school and parent. Other advantages mentioned were the fact that all information was in one place and that "information can be accessed anytime"; the positive effect on his/her child's self-reliance; the useful app on his/her phone making it easy to see which homework or assessments are due; and a lighter school bag.

The findings described above indicate that parents lose control over fulfilling their responsibility with regards to their children's educational needs. Future research could include a deeper theoretical understanding of this phenomenon by using a theory such as the Perceptual Control Theory (PCT). The Perceptual Control Theory (PCT) is a theory of behaviour derived from control theory, with the core principle being that "all behaviour is the control of perception" (Farrell, Hollands, Taylor, \& Gamble, 1999). It could be used to explain the perceptual control parents have over their children's educational development using the technology implemented by the school.

\section{Conclusion}

The findings illustrate the important role played by parents in the educational development of their children (especially children in the primary school). The change management process, when implementing technology in schools, should therefore 
recognise, apart from teachers and learners, the parents as key stakeholders. The negative attitudes of parents towards technology implementation in schools might have an influence on their children's adoption of the technology in the classroom. On the other hand, parents can give valuable feedback on the practicalities and difficulties experienced because of the technology integration. Although the use of technology changes the interaction between parents, teachers and learners, this triad remains at the heart of successful education.

\section{$7 \quad$ References}

Cavanaugh, T. (2002). EBooks and Accommodations: Is this the future of print accommodations? Teaching Exceptional Children, 35(2), 56-61.

Clarke, V., \& Braun, V. (2013). Teaching thematic analysis: Over- coming challenges and developing strategies for effective learning. Psychologist, 26(2), 120-123.

Coates, H., James, R., \& Baldwin, G. (2005). A Critical Examination of the Efects of Learning Management Systems on University Teaching and Learning. Tertiary Education and Management, 11, 19-36.

Embong, A., Noor, A., Rafek, M., Othman, H., Zarina, P., \& Khalid, M. (2014). What do Teachers and Pupils Say about Using e-books in the classrooms? International Journal of Social Science and Humanity, 4(6), 451-457.

Farrell, P., Hollands, J., Taylor, M., \& Gamble, H. (1999). Perceptual Control and Layered Protocols in Interface Design: I. Fundamental Concepts. International Journal of Human-Computer Studies, 50, 489-520.

Kinshuk, Huanh, H., Sampson, D., \& Chen, N.-S. (2013). Trends in Educaional Technology through the Lens of the Highly Cites Articles published in the Journal of Educational Technology and Society. Eduational Technology \& Society, 16(2), 3-20.

Lam, P., Lam, S. L., Lam, J., \& McNaught, C. (2009). Usability and Usefulness of eBooks on PPCs: How students' opinions vary over time. Australian Journal of Educational Technology, 25(1), 30-44.

Landoni, M., Wilson, R., \& Gibb, F. (2000). From the visual book to the web book: the importance of design. The Electronic Library, 18(6), 407-419.

Lim, C., Zhao, Y., Tondeur, J., Chai, C., \& Tsai, C. (2013). Bridging the Gap: Technology Trends and Use of Technology in Schools. Journal of Educational Technology \& Society, 16(2), 59-68.

Ng, W., \& Nicholas, H. (2013). A framework for sustainable mobile learning in schools. British Journal of Educational Technology, 44(5), 695 - 715.

Spector, J. (2013). Emerging Education Technologies and Research Directions. Educational Technology \& Society, 16(2), 21-30.

Weilbach, L., \& Matthee, M. (2016). Understanding Change from a Socio-technical Perspective. International Journal of Systems and Society, 3(1), 80-93. doi: 10.4018/ijss.2016010106

Windschitl, M., \& Sahl, K. (2002). Tracing Teachers' Use of Technology in a Laptop Computer School: The Interplay of Teacher Beliefs, Social Dynamics, and Institutional Culture. American Eucational Research Journal, 39(1), 165-205. 
Zhao, Y., \& Cziko, G. A. (2001). Teacher Adoption of Technology: A Perceptual Control Theory Perspective. Journal of Technology and Teacher Education, 9(1), 5-30. 